\title{
Ethnic Label Use in Adolescents from Traditional and Non-Traditional Immigrant Communities
}

\author{
Lisa Kiang $\cdot$ Krista M. Perreira $\cdot$ Andrew J. Fuligni
}

Received: 16 June 2010/Accepted: 8 October 2010/Published online: 30 October 2010

(c) The Author(s) 2010. This article is published with open access at Springerlink.com

\begin{abstract}
Understanding adolescents' use of ethnic labels is a key developmental issue, particularly given the practical significance of identity and self-definition in adolescents' lives. Ethnic labeling was examined among adolescents in the traditional immigrant receiving area of Los Angeles (Asian $n=258$, Latino $n=279$ ) and the non-traditional immigrant receiving area of North Carolina (Asian $n=165$, Latino $n=239$ ). Logistic regressions showed that adolescents from different geographic settings use different ethnic labels, with youth from NC preferring heritage and panethnic labels and youth from LA preferring hyphenated American labels. Second generation youth were more likely than first generation youth to use hyphenated American labels, and less likely to use heritage or panethnic labels. Greater ethnic centrality increased the odds of heritage label use, and greater English proficiency increased the odds of heritage-American label use. These associations significantly mediated the initial effects of setting. Further results examine ethnic differences as well as links between labels and self-esteem. The discussion highlights implications of ethnic labeling and context.
\end{abstract}

Keywords Ethnic labeling - Ethnic identity - Geographic setting · Adjustment

L. Kiang ( $\bowtie)$

Wake Forest University, P.O. Box 7778,

Winston-Salem, NC 27109, USA

e-mail: KiangL@wfu.edu

K. M. Perreira

UNC-Chapel Hill, Chapel Hill, NC, USA

A. J. Fuligni

UCLA, Los Angeles, CA, USA

\section{Introduction}

In schools and other contexts, adolescents must often select ethnic labels to characterize who they are, for instance, when filling out college applications or applying for a driver's license. Although these official forms typically provide a restricted number of labels that adolescents can select, in reality, there are numerous options and combinations of options that are available. For instance, beyond panethnic terms (e.g., Asian, Hispanic, Latino) that are commonly found on institutional forms and that offer a sweeping sense of identification with a broad cultural group, adolescents could alternatively choose to identify more precisely with their specific ethnic heritage (e.g., Chinese, Mexican, Guatemalan). As yet additional options, adolescents could acknowledge their connection with the mainstream society, for instance, using an "American" label either alone or biculturally in a conjunction with a panethnic or ethnic heritage label (e.g., Asian-American, Mexican-American). Understanding why adolescents may prefer certain ethnic labels over others is not only a key developmental issue but also significant given that the differential use of ethnic labels can have implications for social relationships and well-being (Kiang 2008; Malott et al. 2009).

Given their salience and practical importance in adolescents' lives, ethnic labels have been increasingly used as prominent and meaningful markers of identity (Phinney 2003). However, systematic research on adolescents' labeling choices is still emerging. In particular, there is little knowledge on individual variation in labeling preferences, and on how patterns of ethnic label use can be tied to the contexts and communities in which adolescents reside. The current study incorporated data from four ethnically and geographically diverse samples to explore 
whether ethnic label use varies by adolescents who live in large metropolitan areas that have long been ethnically diverse in comparison to their counterparts in both urban and rural communities that are newly adapting to having an immigrant population. Specifically, we make contextual comparisons between adolescents with Asian and Latin American backgrounds residing in non-traditional immigrant receiving sites in North Carolina and those in Los Angeles, an area with an established history of hosting immigrant families. We also investigate main effects of ethnicity on ethnic label use. In addition, we examine generational status, language proficiency, and ethnic centrality and regard as key factors that may contribute to individual variation in ethnic label use and as potential mediators of any main effects of geographic setting or ethnicity that are found. Finally, we examine whether ethnic label use relates to a key indicator of psychological adjustment, namely, self-esteem. We conclude with a discussion of the uses and implications of ethnic labels chosen by adolescent immigrants to define themselves.

\section{Contextual Considerations in Ethnic Labeling}

From an ecological perspective (Bronfenbrenner 1979), adolescents' use of ethnic labels may be determined by the geographic setting in which they reside. A combination of contextual factors, for instance, the social reception of the immigrant receiving community, racial discrimination in schools and neighborhoods, the size, connectedness, and ethnic diversity of the community, can all structure adolescents' daily experiences and ultimately shape the way youth define themselves (Portes and Rumbaut 2001). Despite the importance of context in adolescents' lives, existing research on ethnic identity development has been limited in its virtually exclusive focus on individuals from large, ethnically diverse cities such as New York or Los Angeles.

Historically, immigrant families have predominately settled in population-dense, metropolitan locations. In some of these communities, such as Los Angeles, there was a Latino population long before there was an Anglo population, and these families with Latino ancestry are typically well-integrated into their local communities (Perreira et al. 2010). Similarly, immigrants from Asia in the early 1900s largely entered through the Angel Island gateway in northern California and ultimately settled in San Francisco and other parts of the state. Given their long history of settlement in such West Coast urban areas, adolescents from these immigrant families tend to be fairly wellacculturated today. Currently, many individuals from both Asian and Latino backgrounds in areas like Los Angeles have a strong, integrated presence not only in their neighborhoods and communities but also within the school system, local businesses and services, and even the political environment through community-elected offices. These experiences contrast notably with those found in emerging immigrant communities.

Immigrant families are increasingly settling in less saturated areas with greater economic opportunities (Massey and Capoferro 2008; Parrado and Kandel 2008). For instance, over the last two decades, immigrants from Latin American backgrounds have steadily settled in the US Midwest and South (Suro and Tafoya 2004), with North Carolina leading these new settlement areas in growth (Perry and Schachter 2003). Immigrants from Asia are also increasingly settling in regions like the Midwest or South more so than others (e.g., West, Northeast) (US Census 2004). In North Carolina, individuals with Asian ancestry tripled in number around the turn of the century, yet still comprise only $2 \%$ of the population, statewide (Reeves and Bennett 2003). Areas like North Carolina that are new to hosting immigrants are known as nontraditional immigrant receiving sites. Such areas are typically characterized by small, low population-dense cities and rural towns, and often have few resources and infrastructures that support adolescents' integration into their communities (Bailey 2005; Hirschman and Massey 2008).

Within ethnically diverse communities, such as in traditional immigrant receiving areas like Los Angeles, adolescents may have diverse ethnic labels to choose from. In such communities, it may be relatively normative to claim multifaceted forms of ethnic identification and, as such, adolescents may feel free to use any combination of American, panethnic, or heritage ethnic labels (Qian 2004). Among non-traditional immigrant receiving sites, the limited ethnic diversity may motivate adolescents with Asian and Latino ancestry to increase their minority representation by aligning themselves in a broad, panethnic manner. Indeed, panethnic movements found among Asian communities commonly stem from the motivation for diverse Asian nationals to strengthen their social power and increase their overall presence (Espiritu 1992; Kibria 2000; Okamoto 2006). On the other hand, due to the salience of being in the ethnic minority, adolescents' ethnic status may be more prominent in non-traditional receiving sites. As a result, youth may identify more strongly with their ethnic backgrounds, and feel more reserved about identifying as an American or attaching an American label to their heritage or panethnic choices. In addition, given the few institutional resources that are available to families in nontraditional immigrant receiving areas, parents may frequently enlist their adolescent children to assist with language brokering or translations. This assistance can help foster a strong ethnic connection in these youth (Morales and Hanson 2005; Orellana 2003), perhaps motivating 
them to identify closely with their specific culture and ancestry.

In the current study, we explored these competing expectations and addressed how context structures adolescents' ethnic labeling preferences. Specifically, we examined patterns of ethnic labeling among four groups: (1) adolescents from Asian backgrounds recruited from the traditional immigrant receiving area of Los Angeles, (2) adolescents from Latin American backgrounds from Los Angeles, (3) adolescents from Asian backgrounds from the non-traditional immigrant receiving area of North Carolina, and (4) adolescents from Latin American backgrounds from North Carolina. We investigated questions of ethnic labeling and adjustment across these subsamples with the intent of better understanding the cultural identity formation of youth from similar ethnic backgrounds living in different geographic contexts, as well as youth with different ethnicities living in the same understudied region of the Southeastern U.S.

\section{Individual Differences in Ethnic Labeling}

Beyond context, individual characteristics may influence adolescents' choice of ethnic labels. Prior research on ethnic labeling has largely focused on generational status, with country of birth appearing to validate the use of certain labels (Phinney 2003). For instance, first generation (i.e., foreign-born) youth are more likely to use ethnic heritage labels compared to their second and third generation peers (i.e., American-born), who tend to use panethnic or hyphenated American labels (Fuligni et al. 2008; Rumbaut 1994). Such patterns have been found in samples from both Latin American (Buriel and Cardoza 1993; Zarate et al. 2005) and Asian backgrounds (Kiang 2008; Masuoka 2006).

Similar to generational differences, language proficiency could reinforce youths' ethnic identities (Phinney et al. 2001). Among adults with Chinese ancestry, greater English proficiency decreased the likelihood of using ethnic heritage labels (Kiang 2008). Among youth from both Asian and Latin American backgrounds, greater heritage language proficiency was linked with a decreased tendency to use an American label (Fuligni et al. 2008). Hence, greater facility with the language of one's ethnic group appears to relate to a strong identification with one's ethnic group, whereas English proficiency may motivate adolescents to more strongly identify with mainstream America and loosen ties with one's heritage culture.

Individual differences related to ethnic centrality and regard, two common indicators of ethnic identity, may also be linked to ethnic label use. Fuligni et al. (2005) found that ethnic centrality, the importance one places on ethnic group membership, was higher in adolescents from Asian and Latin American backgrounds who chose ethnic heritage labels as compared to those who identified panethnically. Perhaps adolescents who consider their ethnicity a central component in their lives engage in more active efforts to learn about their ethnic group and ultimately feel strongly connected to their ethnic heritage (Kiang 2008). For those whose ethnicity is less central, perhaps using a more general, panethnic default is sufficient. Similarly, ethnic regard or feeling positively about one's ethnic group has been also linked to lower inclusion of panethnic and American labels in youth from Asian and Latino backgrounds (Fuligni et al. 2008). These emerging findings suggest that the adolescents who identify most strongly with their specific ethnic heritage tend to also report stronger positive feelings about their ethnic group and consider their ethnicity to be an important aspect of the self.

Ethnic Labeling and Adjustment

Research on ethnic identity, as indicated by measures such as ethnic centrality and regard, has supported direct and indirect links with well-being (Ryff et al. 2003; Sellers et al. 1997). Do ethnic labels have similar adjustment implications? From an acculturation perspective, individuals who are bicultural have been found to report positive adjustment outcomes due to their comfort and ability in successfully navigating multiple cultural contexts (Berry 2003; LaFromboise et al. 1993). Perhaps youth who choose a combination of heritage and American labels will report higher self-esteem compared to those who choose singular labels to describe themselves. Positive adjustment also may be more closely linked with heritage labels than panethnic ones, due to a more precise sense of social connectedness that is linked with a specific group affiliation. Some support for this idea has been found in recent work whereby adults who used Chinese American labels reported higher selfesteem than those who preferred Asian American labels (Kiang 2008).

\section{Summary of the Current Study}

Our goal was to integrate four datasets that include similar methods and measures but center on different ethnic and geographic samples to examine contextual and individual factors that contribute to adolescents' ethnic label use. Due to the salience of being in the ethnic minority, we expected that youth from non-traditional areas of migration (e.g., North Carolina) would be less likely than their counterparts in Los Angeles to use American labels to define themselves, instead preferring ethnic heritage or panethnic 
labels. Although ethnic differences were explored, we expected geography to trump ethnicity. That is, due to qualitatively different experiences of residing in traditional versus emerging immigrant communities, we expected that youth from Asian and Latin American backgrounds living in one geographic location would be more similar than adolescents with same-ethnic backgrounds living in two different regions.

We also examined whether individual factors such as generation, language proficiency, and ethnic identity contribute to ethnic label choice and mediate any initial effects of setting or ethnicity. US-born youth (e.g., second or third generation) were expected to shed their ethnic heritage labels and be more likely to use panethnic and American labels compared to those of the first generation. English proficiency was expected to contribute to American label use, whereas heritage language proficiency was expected to contribute to heritage label use. Ethnic identity, measured through centrality and regard, was anticipated to predict ethnic heritage labels, due to the "identity work" involved in maintaining close ties to one's ethnic background. Lastly, we examined links between ethnic labels and psychological adjustment, as measured by self-esteem. Based on ethnic identity and acculturation research, we expected that higher self-esteem would be linked to the use of ethnic heritage labels and labels that incorporate both ethnic and American identities.

\section{Methods}

Data were drawn from multiple studies that were designed in concert with one another to be conceptually and methodologically similar. The Social Identification and Academic Adaptation study systematically examined adolescents in the Los Angeles area with Asian, Latin American, and European ancestry. The Southern Immigrant Adaptation and Adjustment study was essentially a replication that focused on adolescents with Latin American ancestry residing in nontraditional immigrant receiving areas of North Carolina. A parallel study, Purpose and Meaning in Adolescents' Daily Lives, focused on adolescents with Asian ancestry in North
Carolina. Each study includes at least one wave of daily diary data and questionnaires assessed longitudinally. Table 1 summarizes basic demographic information across subsamples, as described below. Notably, the only demographic variable that was found to vary by setting was generational status. Specifically, there were more adolescents from the second and third generations in LA compared to $\mathrm{NC}$ $\left(\chi^{2}(1)=.62 .70, p<.001\right)$.

\section{Participants}

Los Angeles Asian and Latin American Samples (LA-Asian, LA-Latino)

Two samples of adolescents drawn from three public high schools in the Los Angeles area: 258 with Asian ancestry (48\% female) and 279 with Latin American ancestry (52\% female). All were in the ninth grade. The mean age across both samples was 14.85 . About $31 \%$ of Asian and $19 \%$ of Latino adolescents were of the first generation (i.e., foreign-born). Remaining participants were mostly of the second generation (i.e., US-born), and a smaller proportion was of the third generation. For ease of generational comparisons, adolescents from the second and third generations were combined. Approximately $86 \%$ of those with Latin American ancestry had Mexican heritage and $67 \%$ of those with Asian ancestry had Chinese heritage. Other ethnic heritages included Guatemalan, Honduran, Salvadoran, Indian, Taiwanese, or Vietnamese.

\section{North Carolina Asian Sample (NC-Asian)}

There were 165 ninth (50\%) and tenth grade adolescents with Asian ancestry recruited from six public high schools in central North Carolina. The mean age was 14.97. Approximately $58 \%$ was female and $25 \%$ was of the first generation. The remaining $75 \%$ was second generation. Adolescents represented several self-reported heritage groups: 28\% Hmong, 22\% multiethnic (mostly within Asian groups, e.g., Cambodian and Chinese), 11\% Asian Indian, 8\% Chinese, 8\% panethnic (e.g., Asian), and
Table 1 Demographic characteristics across subsamples

\begin{tabular}{lllll}
\hline & $\begin{array}{l}\text { LA-Asian, } \\
n=258\end{array}$ & $\begin{array}{l}\text { LA-Latino, } \\
n=279\end{array}$ & $\begin{array}{l}\text { NC-Asian, } \\
n=165\end{array}$ & $\begin{array}{l}\text { NC-Latino, } \\
n=239\end{array}$ \\
\hline $\begin{array}{l}\text { Females } \\
\text { Mean age }\end{array}$ & $48 \%$ & $52 \%$ & $58 \%$ & $54 \%$ \\
Generational status & 14.87 & 14.83 & 14.97 & 15.32 \\
First & $31 \%$ & $18 \%$ & $25 \%$ & $67 \%$ \\
Second & $63 \%$ & $57 \%$ & $75 \%$ & $30 \%$ \\
Third & $6 \%$ & $25 \%$ & $0 \%$ & $4 \%$ \\
Lives with two parents & $72 \%$ & $59 \%$ & $78 \%$ & $58 \%$ \\
\hline
\end{tabular}


the remaining $23 \%$ represented small clusters such as Montagnard, Laotian, Vietnamese, or Korean.

\section{North Carolina Latin American Sample (NC-Latino)}

Approximately 239 ninth graders with Latin American ancestry were recruited from nine public high schools in central North Carolina (54\% female). About $68 \%$ was of the first generation, and the remaining $32 \%$ was US-born of either the second or third generation. The mean age was 15.32. Approximately $53 \%$ had Mexican ancestry and the remaining adolescents were represented by ethnic subgroups from Central and South America (e.g., Honduran, Salvadoran, Nicaraguan).

\section{Procedures}

Procedures were similar across each study. Adolescents were invited to participate in a study of social development and adaptation and parental consent and adolescent assent were obtained prior to participation. In small groups at school, students completed a packet of self-report questionnaires, which assessed a variety of sociocultural indicators of adjustment (e.g., ethnic identity, academic motivation, psychological well-being, family relationships) and took about 40-50 min to complete. Adolescents were also given a 14-day supply of daily diary checklists to complete at home. The current study focused solely on the questionnaires assessed at school. Students were given a small amount in cash or in a retail gift card for participating. Overall response rates were similar across all four samples and ranged from about $60-65 \%$.

\section{Measures}

\section{Ethnic Labeling}

In an open-ended response format, students were asked to indicate the single ethnic label that they believed best described them. Adolescents were allowed to report more than one label if they felt that it was most accurate for their own ethnic identity, but this was done by a negligible number of participants. From these responses, five dummy variables $(0=n o, 1=$ yes $)$ were created to reflect whether an ethnic heritage label (e.g., Mexican, Chinese, Guatemalan, Hmong), a panethnic label (e.g., Asian, Latino), or an American label, either by itself or hyphenated and paired with a heritage or panethnic label (e.g., American, Mexican-American, Asian-American) was included. This classification scheme was mutually exclusive.
Language Proficiency

Using standard approaches to measuring self-reported language proficiency (e.g., Phinney et al. 2001; Portes and Rumbaut 2001), adolescents listed all of the languages spoken in their home. For any non-English language indicated (e.g., Chinese, Spanish), participants were asked to rate how well they speak, understand, read, and write that language. Items were on a five-point scale $(1=$ "Not very well," 5 = "Very well"), and responses to these multiple items of proficiency were averaged. Participants received a 0 on this scale if they indicated that no non-English languages were spoken in their home, resulting in a scale that ranged from 0 to 5 . Similar items were rated with respect to English proficiency. Internal consistencies were similar for all four samples ( $\alpha \mathrm{s}=.86$ to .89 ).

Ethnic Centrality and Regard

Adapted subscales from the Multidimensional Inventory of Black Identity (MIBI; Sellers et al. 1997) were used to measure ethnic centrality and regard. Centrality, with 7 items, refers to the degree to which adolescents felt that their ethnicity is central to their overall sense of self. Sample items read, "In general, being a member of my ethnic group is an important part of my self-image," and, "Being a part of my ethnic group is an important reflection of who I am." Regard refers to the extent to which adolescents have positive feelings toward their ethnic group. There are 8 items and sample items read, "I feel good about the people in my ethnic group," and, "I believe that I have many strengths because I am a member of my ethnic group." All items were scored on a 5-point scale ranging from Strongly Disagree to Strongly Agree with higher scores reflecting higher levels of centrality and regard. Internal consistencies ranged from $\alpha=.65$ to .72 across all samples.

Self-esteem. In all samples, global self-esteem was assessed using the Rosenberg self-esteem scale (Rosenberg 1965). Ten items were rated on a 5-point scale ranging from Strongly Disagree to Strongly Agree, with higher values indicating higher self-esteem. Sample items include, "I feel that I have a number of good qualities," and, "I take a positive attitude towards myself." Internal consistencies were $\alpha=.72$ to .86 across the four samples.

\section{Results}

Patterns of Ethnic Label Use and Differences in Study Variables by Sample

As indicated above, we conducted a mutually-exclusive coding of adolescents' choice of the "best ethnic label" 
Table 2 Frequencies and means (SDs) in primary study variables by subsample

\begin{tabular}{llllr}
\hline & $\begin{array}{l}\text { LA-Asian, } \\
n=258\end{array}$ & $\begin{array}{l}\text { LA-Latino, } \\
n=279\end{array}$ & $\begin{array}{l}\text { NC-Asian, } \\
n=165\end{array}$ & $\begin{array}{l}\text { NC-Latino, } \\
n=239\end{array}$ \\
\hline Ethnic labels & & & & \\
$\quad$ Heritage & $30.2 \%$ & $23.7 \%$ & $56.4 \%$ & $55.2 \%$ \\
Heritage-American & $35.1 \%$ & $38.4 \%$ & $10.3 \%$ & $7.9 \%$ \\
Panethnic & $10.1 \%$ & $16.7 \%$ & $14.5 \%$ & $27.6 \%$ \\
Panethnic-American & $21.8 \%$ & $15.5 \%$ & $15.2 \%$ & $6.7 \%$ \\
American only & $2.8 \%$ & $5.7 \%$ & $3.6 \%$ & $2.5 \%$ \\
& & & & \\
Language proficiency & $4.53(.73)$ & $4.70(.55)$ & $4.39(.85)$ & $3.72(1.37)$ \\
English & $2.90(.94)$ & $3.59(1.08)$ & $2.93(.97)$ & $4.23(1.00)$ \\
Heritage & & & & \\
Ethnic identity & $3.27(.82)$ & $3.29(.88)$ & $4.14(.98)$ & $3.83(.78)$ \\
Centrality & $4.01(.64)$ & $4.12(.71)$ & $4.33(.85)$ & $4.41(.63)$ \\
Regard & &
\end{tabular}

that describes them. Heritage refers to specific ethnic heritage or national labels such as Mexican, Hmong, and Chicano. Panethnic refers to broad, general labels such as Latino, Asian, or Hispanic. Heritage-American and Panethnic-American refers to the use of a Heritage or Panethnic label in conjunction with American. Percentages of adolescents reporting these categories of ethnic labels are listed in Table 2 and illustrated in Fig. 1. As shown, higher percentages of heritage label use were found for NC adolescents with Asian and Latino ancestry (56.4 and $55.2 \%$, respectively) than those in LA. Youth in NC also appeared less likely to attach an American term to their labels. Within each sample, chi-square analyses revealed that ethnic label choice was not significantly related to gender $\left(\chi^{2}(4)\right.$ range $=.81$ to $\left.6.17, \mathrm{~ns}\right)$.

Levels of language proficiency and ethnic identity reported across samples are also shown in Table 2. A 2 (setting) $\times 2$ (ethnicity) MANOVA was used to examine variable means as outcomes. Results revealed main effects for setting such that NC adolescents reported higher levels of centrality $(F(1,825)=132.19, p<.001$, partial $\left.\eta^{2}=.14\right)$ and regard $(F(1,825)=34.77, p<.001$, partial $\left.\eta^{2}=.04\right)$ compared to LA youth. In addition, NC youth

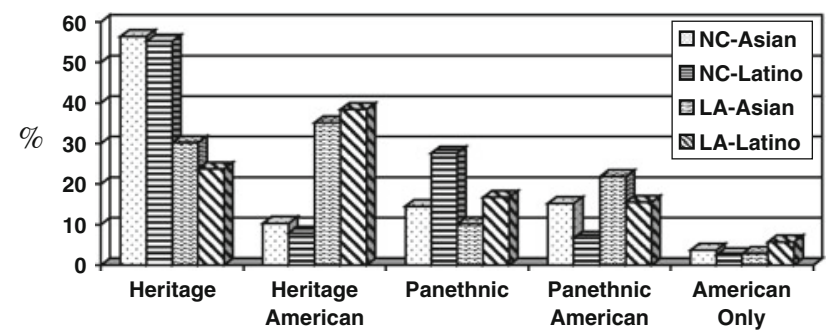

Fig. 1 Frequency of adolescents' ethnic labeling choices by subsample reported lower levels of English proficiency $(F(1,825)=$ 59.58, $p<.001$, partial $\left.\eta^{2}=.07\right)$ and higher levels of heritage language proficiency $(F(1,825)=22.84, p<$ .001 , partial $\left.\eta^{2}=.03\right)$ than youth in LA. Main effects of ethnicity were also found whereby adolescents with Asian ancestry reported higher English proficiency $(F(1,825)=$ $10.85, p<.05$, partial $\left.\eta^{2}=.01\right)$, lower heritage language proficiency $\left(F(1,825)=206.73, p<.001\right.$, partial $\eta^{2}=$ $.20)$, and lower centrality $(F(1,825)=5.29, p<.05$, partial $\left.\eta^{2}=.01\right)$, and lower ethnic regard $(F(1,825)=$ 6.70, $p<.01$, partial $\left.\eta^{2}=.01\right)$ than those with Latin American ancestry.

Several interactions were also found. Ethnic differences in English proficiency $(F(1,825)=33.10, p<.001$, partial $\left.\eta^{2}=.04\right)$ and heritage language proficiency $(F(1,825)=$ $19.22, p<.001$, partial $\eta^{2}=.02$ ) were greater among $\mathrm{NC}$ youth than in LA. A setting by ethnicity interaction was also found with respect to centrality such that, within $\mathrm{NC}$, adolescents with Asian ancestry reported higher levels of centrality than their counterparts with Latin American ancestry but, in LA, adolescents with Asian ancestry reported lower levels of centrality than their Latin American counterparts $(F(1,825)=10.38, p<.001$, partial $\left.\eta^{2}=.01\right)$. No other main effects or interactions were found. Collectively, these results support the value of considering geographic setting in adolescents' lives and suggest that initial effects of setting or ethnicity on ethnic labeling may be explained by language or ethnic identity.

Logistic Regressions Predicting Ethnic Label Use

A series of logistic regressions was used to examine differential predictors of ethnic labels. Due to the few adolescents who chose an American label alone, each model focused on predicting heritage, heritage-American, panethnic, or 
panethnic-American labels. We examined independent predictors of geographic setting and ethnicity by effect coding $(\mathrm{LA}=-1, \mathrm{NC}=1$; Latino $=-1$, Asian $=1)$ and entering each variable in Block 1 of our models. Effect coding was used for ease of interpretability. Notably, in preliminary analyses, we also examined two-way interactions between setting and ethnicity. None were significant and, hence, were not included in our final models. In Block 2, we tested the main and meditational effects of generational status (effect coded with first generation $=-1$, second and third generations $=1$ ), English and heritage language proficiency, and ethnic centrality and regard.

As shown in Table 3, geographic setting was consistently associated with ethnic labeling. The odds of choosing a heritage or panethnic label significantly increased by factors of 1.90 and 1.36, respectively, for adolescents from NC compared to LA. In contrast, residing in NC decreased the odds of using a heritage-American label or a panethnicAmerican label by factors of .43 and .75 , respectively. Main effects of ethnicity were also found whereby adolescents with Asian ancestry were significantly less likely to use a panethnic label $(\mathrm{OR}=.70)$ and more likely to use a panethnic-American label $(\mathrm{OR}=1.35)$ compared to youth with Latin American ancestry.

Above and beyond main effects of setting and ethnicity, generational status emerged as a significant predictor of ethnic labels. As shown in Block 2 of our models, adolescents of later generations were less likely to use heritage or panethnic labels (ORs $=.58$ and .79 , respectively) and more likely to use heritage-American or
panethnic-American labels $\quad(\mathrm{ORs}=1.60$ and 2.28, respectively) compared to adolescents of the first generation. English proficiency also emerged as a significant predictor of heritage-American labels, with each unit increase in proficiency increasing the odds of using a heritage-American label by a factor of 1.63. In addition, each unit increase in ethnic centrality was associated with increased odds of choosing a heritage label (OR $=1.34$ ). The addition of variables in Block 2 uncovered a significant effect of ethnicity. The likelihood of choosing a heritage label increased by a factor of 1.28 for youth with Asian ancestry compared to those with Latin American ancestry.

We further examined whether these significant effects of generation, ethnic centrality, and English proficiency mediated the initial differences found by geographic setting and ethnicity. Using procedures for dichotomous predictors outlined by MacKinnon and Dwyer (1993), Sobel tests confirmed that generational status mediated a significant portion of the initial effect of setting on the use of heritage $(z=4.84, \quad p<.001), \quad$ heritage-American $(z=-3.36$, $p<.001)$, panethnic $(z=2.02, p<.05)$, and panethnicAmerican labels $(z=-4.09, p<.001)$. Generation also significantly mediated the effect of ethnicity on the use of panethnic $(\mathrm{z}=-2.01, p<.05)$ and panethnic-American labels $(z=3.18, p<.001)$. In addition, ethnic centrality significantly mediated the initial effect of setting $(z=2.52$, $p<.01)$ on the use of heritage labels. English proficiency significantly mediated the effect of setting on the use of heritage-American labels $(z=-2.94, p<.01)$.

Table 3 Logistic regressions predicting ethnic labels by setting, ethnicity, and potential mediators

\begin{tabular}{|c|c|c|c|c|c|c|c|c|}
\hline & \multicolumn{2}{|l|}{ Heritage } & \multicolumn{2}{|c|}{ Heritage-Am. } & \multicolumn{2}{|l|}{ Panethnic } & \multicolumn{2}{|l|}{ Pan-Am. } \\
\hline & $b(\mathrm{SE})$ & OR & $b(\mathrm{SE})$ & OR & $b(\mathrm{SE})$ & OR & $b(\mathrm{SE})$ & OR \\
\hline \multicolumn{9}{|l|}{ Block 1} \\
\hline Setting & $.64(.08)$ & $1.90 * * *$ & $-.84(.10)$ & $.43 * * *$ & $.31(10)$ & $1.36 * *$ & $-.28(.11)$ & $.75 * *$ \\
\hline Ethnicity & $.13(.08)$ & $1.13 \dagger$ & $.02(.09)$ & 1.08 & $-.36(.10)$ & $.70 * * *$ & $.30(.10)$ & $1.35 * *$ \\
\hline \multicolumn{9}{|l|}{ Block 2} \\
\hline Setting & $.60(.08)$ & $1.82 * * *$ & $-.64(.11)$ & $.53 * * *$ & $.24(.10)$ & $1.27 *$ & $-.23(.11)$ & $.80^{*}$ \\
\hline Ethnicity & $.25(.08)$ & $1.28 * *$ & $.07(.10)$ & 1.07 & $-.33(.10)$ & $.72 * * *$ & $.28(.11)$ & $1.32 *$ \\
\hline Generation & $-.55(.09)$ & $.58 * * *$ & $.47(.12)$ & $1.60 * * *$ & $-.24(.11)$ & $.79 *$ & $.82(.17)$ & $2.28 * * *$ \\
\hline English & $-.07(.09)$ & .93 & $.49(.16)$ & $1.63 * *$ & $-.11(.10)$ & .90 & $.22(.18)$ & 1.25 \\
\hline Heritage Lang. & $.10(.08)$ & 1.11 & $.10(.10)$ & 1.10 & $-.02(.10)$ & .98 & $-.04(.11)$ & .97 \\
\hline Centrality & $.29(.12)$ & $1.34 *$ & $-.14(.13)$ & .87 & $-.19(.14)$ & .83 & $-.07(.16)$ & .94 \\
\hline Regard & $.14(.14)$ & 1.15 & $-.18(.16)$ & .84 & $-.05(.17)$ & .96 & $.11(.20)$ & 1.12 \\
\hline Predictability (\%) & 68.3 & & 77.2 & & 83.2 & & 86.2 & \\
\hline Predicted $n$ & 362 & & 217 & & 156 & & 133 & \\
\hline
\end{tabular}

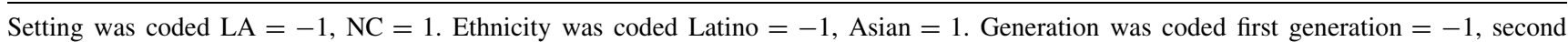
generation $=1$. OR $=$ odds ratio

$\dagger p<.10 ; * p<.05 ; * * p<.01 ; * * * p<.001$ 
Ethnic Label Use and Self-Esteem

We categorized adolescents' ethnic label use $(1=$ heritage, $2=$ heritage-American, $3=$ panethnic, $4=$ panethnic-American) for consideration as a fixed factor in an ANOVA predicting self-esteem. Main and moderating effects of setting and ethnicity were also examined. Although no main effect of label choice was found $(F(3,834)=2.03, \mathrm{~ns})$, there were main effects of setting $(F(1,834)=4.59, p<.05)$ and ethnicity $(F(1,834)=$ $14.60, p<.001)$. Adolescents in NC reported significantly higher self-esteem $(M=3.90, \mathrm{SD}=.80)$ than their LA counterparts $(M=3.78, \quad \mathrm{SD}=.74)$. Adolescents with Latin American ancestry reported significantly higher selfesteem $(M=3.95, \mathrm{SD}=.78)$ than their counterparts with Asian ancestry $(M=3.73, \mathrm{SD}=.73)$. Notably, these main effects remained significant even after adding adolescent generational status as a covariate, further supporting the importance of context in differentiating outcomes for immigrant youth. No interactions between setting, ethnicity, or label use were found.

\section{Discussion}

A fundamental developmental task requires adolescents to explore and determine where they fit in the world around them (Erikson 1968) and, in doing so, adolescents' ethnic identity development may drive them to experiment with the use of different ethnic labels (Phinney 2003). Given the salience of identity development during adolescence and the prevalence of school forms and other official documents that require youth to repeatedly think about the different ethnic labels that best define them, the present study sought to understand the patterns and correlates of adolescents' ethnic labeling preferences. We drew from complementary, yet distinct, datasets focusing on youth with Asian and Latin American ancestry who reside in different US geographic locations to make comparisons by both contextual setting and ethnicity.

Several notable patterns in adolescents' ethnic labeling choices were found. First, in comparison to adolescents in Los Angeles, an area that has long been accustomed to hosting immigrant families, adolescents who reside in nontraditional or emerging immigrant communities in North Carolina overwhelmingly preferred either heritage labels reflective of their specific ethnic background (e.g., Chinese, Hmong, Mexican) or panethnic labels (e.g., Asian, Latino) over hyphenated American ones. These patterns may be motivated by differences in the ethnic diversity of the surrounding environment. That is, adolescents with Asian and Latin American ancestry tend to only contribute about $4-15 \%$ of the total student body in the NC high schools from which our samples were drawn (North Carolina Department of Public Instruction 2008). In contrast, adolescents from Asian and Latin American backgrounds often comprise the numerical majority in high schools in LA (California Department of Education 2006). The strong preference for adolescents from new immigrant communities to identify closely with their specific ethnic heritage may be thus due to the salience of being in the ethnic minority and the "identity work" that may be involved in accepting one's minority status (Fuligni et al. 2008). At the same time, a preference for panethnic labels among youth in new immigrant communities could stem from desires to strengthen their overall presence (Espiritu 1992; Kibria 2000; Okamoto 2006).

The hyphenated American identifications that seemed particularly common among youth in LA suggest that these adolescents endorse a bicultural identity, perhaps due to greater cultural resources that help support their integration into the community. The greater ethnic diversity found in areas like LA may also allow adolescents greater freedom in choosing both American and ethnic labels to define themselves (Qian 2004). For instance, adolescents who feel well-represented in their communities could perceive more flexible options with which to identify as both an "American", and also more specifically with their ethnic group. Established ethnic enclaves (e.g., Chinatown) that are often found in traditional immigrant receiving areas could also serve to encourage youth to maintain a strong identification with their heritage culture.

Differences in adolescent generational status, language proficiency, and ethnic identity were also examined across geographic setting, and implicated as potential explanations for the labeling patterns found. Indeed, there were larger proportions of adolescents from the second and third generations among traditional immigrant receiving areas in LA compared to emerging immigrant communities in NC. In addition, adolescents from NC reported higher levels of ethnic centrality and regard, greater proficiency with a heritage language, and lower proficiency with English. Perhaps the experience of being an ethnic minority in an area where the mainstream culture is still becoming accustomed to immigrant populations increases the salience of adolescents' ethnic backgrounds and encourages them to identify more strongly with their ethnic group. Differences in generational status could also explain some of these other effects found across setting. For instance, adolescents from later generations, such as those from LA, could feel less strongly connected to their ethnic group and, in addition, their language skills could evolve differently as well.

Notably, ethnic differences were also found whereby adolescents with Asian ancestry reported greater English proficiency and weaker heritage language skills, and lower 
ethnic regard compared to their counterparts with Latin American ancestry. However, some of these mean differences were qualified by interactions with settings. For instance, ethnic differences in English proficiency were more pronounced in NC than in LA. Further, adolescents from Asian backgrounds in NC reported greater centrality than their counterparts from Latin American backgrounds, whereas the reverse patterns were found in LA. More systematic research is needed to better disentangle some of these effects; however, our general results suggest that geographic setting plays an intricate role in adolescents' cultural adaptation. Moreover, variables such as generational status and language skills may be responsible for driving some of the broader labeling differences found across locations.

Consistent with prior research (Masuoka 2006; Zarate et al. 2005), generational status was found to be a consistently robust predictor of ethnic labels whereby adolescents of later generations were less likely to use heritage or panethnic labels and more likely to use hyphenated American labels than those of the first generation. Perhaps the use of a heritage or panethnic label alone is validated or legitimized by being foreign-born (Phinney 2003). In contrast, adolescents who are US-born appear to exhibit greater feelings of bicultural identification (Berry 2003), as evident from their preference for American labels in conjunction with an ethnic or panethnic one. To further highlight the importance of nativity in how adolescents define themselves, generational status was found to significantly mediate the initial effect of geographic setting on all four categories of ethnic labels. That is, one reason why adolescents in traditional and non-traditional immigrant receiving areas appear to prefer different ethnic labels is due, in part, to differences in adolescent generational status.

Although ethnic regard and heritage language proficiency were not significantly associated with ethnic labeling, ethnic centrality and English proficiency emerged as significant predictors that also helped mediate some of the ethnic labeling differences found across setting. Specifically, adolescents from NC reported higher ethnic centrality and lower English proficiency compared to their counterparts in LA. In turn, higher centrality increased the odds of using heritage labels by a factor of 1.34. English proficiency increased the odds of using heritage-American labels by a factor of 1.63. These meditational results highlight two key implications. First, the degree to which one's ethnicity is central to the self and the facility of one's language skills appear to vary by place of residence, further supporting the idea that developmental experiences across traditional and non-traditional immigrant receiving areas differentially structure adolescents' lives. Second, ethnic centrality and language proficiency each represent salient markers for identification, perhaps by providing the motivation and validation necessary for self-identifying with certain groups. Hence, adolescents' ethnic labeling preferences appear tied to social and demographic factors as well as to individual differences in language skills and the importance placed on ethnic background.

Indeed, the contexts in which adolescents reside can affect multiple layers of development. We found some support for the proposition that generational status, ethnic centrality, and language skills may mitigate the impact of geographic setting on ethnic labeling. However, it is important to note that the overall effects of setting were still significant in predicting label use above and beyond any mediating effects. Hence, there are likely other factors involved in explaining the robust influence of context. Although some ethnic differences were found, differences by setting were more consistent and salient. That is, adolescents with Asian and Latin American ancestry within each setting appeared more similar than same-ethnic youth across settings. These findings are supportive of recent work that highlights qualitative differences between adolescents' experiences in new versus established immigrant communities (Perreira et al. 2010). That said, some ethnic differences in labeling were found. For instance, youth with Asian ancestry irrespective of setting were less likely to use panethnic labels and more likely to use panethnicAmerican labels compared to youth with Latin American ancestry. Differences in generational status appeared to account, in part, for these ethnic differences.

In terms of adjustment, adolescents from NC reported significantly higher self-esteem than adolescents from LA, further pointing to the necessity of examining place of settlement as a key factor in development. Main effects of ethnicity were also found whereby youth with Latin American ancestry reported higher self-esteem than adolescents with Asian ancestry. Although links between ethnic label use and self-esteem were not found, ethnic labels likely signify more than a box to check when completing an official form. Rather, labels are imbued with meaning for adolescents who use them, and may provide a way for youth to understand how they are viewed by the larger society and how they want to identify themselves to that broader society (Holley et al. 2009). Recent research highlights the importance of school counselors and other important figures in adolescents' lives to honor the ethnic labels that youth choose to define themselves, given the meaning and importance that such labels take on in adolescents' lives (Malott et al. 2009). Clearly, additional efforts to examine links between ethnic label use and wellbeing should be undertaken.

One limitation of the current study is that our analyses were based on self-report data. We also have little information on whether ethnic labels mean something different 
in each community. For instance, identifying one's ancestral origins as "Mexican" could take on a qualitatively different meaning in LA versus NC. Further, there is a great deal of diversity even within each broad area of immigration. That is, not all specific communities within one geographic area are the same; hence, there remains a need for future research in both traditional and non-traditional areas of migration in order to replicate our results and provide more generalizable findings. Indeed, our crosssite comparisons are only an initial exploration into the potential richness of considering how place of settlement impacts adolescent development. For instance, there are specific ethnicities that are found in one place of settlement and not in another, and such differences should be explicitly examined in future work. As one example, the Asian population in NC is partly comprised of individuals who identify as Montagnard, an ethnic minority group from the highlands of Vietnam who have largely settled in areas of NC and not, for instance, California. Future research that uses qualitative data to more deeply explore adolescents' ethnic labeling choices and cultural adaption could be helpful, particularly in ethnic minority and refugee families that tend to be understudied in the current psychological literature.

Another suggestion for future research is to center on younger samples to determine earlier periods of development in which individuals' ethnic labeling begins to take shape. Indeed, emerging work has shown that children as young as pre-kindergarten are beginning to understand issues of race, ethnicity, and discrimination (Brown and Bigler 2005). Given prior work linking family relationships with ethnic identity (Kiang and Fuligni 2009), and the recent push for understanding family ethic socialization (Hughes et al. 2006), research on how the family influences early conceptions of ethnic labeling would be particularly worthwhile. Similarly, examining how ethnic labeling continues to evolve in later years of high school and through the adult years as adolescents begin post-secondary education or enter the work force could also lead to more precise information on how ethnic labels form and affect other aspects of development.

As long as US convention continues to require classifications by race or ethnicity, the labels that adolescents use to define themselves will likely continue to be a salient aspect of their lives. Much of our understanding of the cultural adaptation of adolescents from immigrant families stem from areas of the US that are relatively ethnically diverse and metropolitan in nature. Consistent with prior research that points to the importance of considering immigrant families' place of settlement and the limited social and institutional resources that are found in new immigrant communities (Bailey 2005; Hirschman and Massey 2008), our results suggest that context plays a significant role in adolescents' cultural self-views. By broadening our understanding of adolescents' ethnic identity development to areas of the US that are newly adapting to a diverse ethnic community, we can move towards nationwide efforts to support development and provide a welcoming environment with which all youth can flourish.

Open Access This article is distributed under the terms of the Creative Commons Attribution Noncommercial License which permits any noncommercial use, distribution, and reproduction in any medium, provided the original author(s) and source are credited.

\section{References}

Bailey, R. (2005). New immigrant communities in the North Carolina Piedmont Triad: Integration issues and challenges. In E. M. Gozdziak \& S. F. Martin (Eds.), Beyond the gateway: Immigrants in a changing America (pp. 57-86). Lanham: Lexington Books.

Berry, J. W. (2003). Conceptual approaches to acculturation. In K. M. Chun, P. B. Organista, \& G. Marin (Eds.), Acculturation: Advances in theory, measurement, and applied research (pp. 17-37). Washington, DC: American Psychological Association.

Bronfenbrenner, U. (1979). The ecology of human development: Experiments by nature and design. Cambridge, MA: Harvard University Press.

Brown, C. S., \& Bigler, R. S. (2005). Children's perceptions of discrimination: A developmental model. Child Development, 76, 533-553.

Buriel, R., \& Cardoza, D. (1993). Mexican American ethnic labeling: An intrafamilial and intergenerational analysis. In M. Bernal \& G. Knight (Eds.), Ethnic identity (pp. 197-210). Albany, NY: State University of New York Press.

California Department of Education. (2006). School summary data. Retrieved January 27, 2006, from http://dq.cde.ca.gov/ dataquest/.

Erikson, E. H. (1968). Identity: Youth and crisis. New York: Norton. Espiritu, Y. (1992). Asian American panethnicity: Bridging institutions and identities. Philadelphia, PA: Temple University Press.

Fuligni, A. J., Witkow, M. R., \& Garcia, C. (2005). Ethnic identity and the academic adjustment of adolescents from Mexican, Chinese, and European backgrounds. Developmental Psychology, 41, 799-811.

Fuligni, A. J., Witkow, M. R., Kiang, L., \& Baldelomar, O. A. (2008). Stability and change in ethnic labeling among adolescents from Asian and Latin American immigrant families. Child Development, 79, 944-956.

Hirschman, C., \& Massey, D. S. (2008). Peoples and places: The new American Mosaic. In D. S. Massey (Ed.), New faces in new places: The changing geography of American immigration (pp. 1-21). New York: Russell Sage Foundation.

Holley, L., Salas, L., Marsiglia, F., Yabiku, S., Fitzharris, B., \& Jackson, K. F. (2009). Youth of Mexican descent of the Southwest: Exploring differences in ethnic labels. Children \& Schools, 31, 15-26.

Hughes, D., Rodriguez, J., Smith, E. P., Johnson, D., Stevenson, H. C., \& Spicer, P. (2006). Parents' ethnic-racial socialization practices: A review of research and directions for future study. Developmental Psychology, 42, 747-770.

Kiang, L. (2008). Ethnic self-labeling in young adults from Chinese American backgrounds. Journal of Youth and Adolescence, 37, 97-111. 
Kiang, L., \& Fuligni, A. J. (2009). Ethnic identity and family processes in adolescents with Latin American, Asian, and European backgrounds. Journal of Youth and Adolescence, 38, 228-241.

Kibria, N. (2000). Race, ethnic options, and ethnic binds: Identity negotiations of second-generational Chinese and Korean Americans. Sociological Perspectives, 43, 77-95.

LaFromboise, T., Coleman, H. L., \& Gerton, J. (1993). Psychological impact of biculturalism: Evidence and theory. Psychological Bulletin, 114, 395-412.

MacKinnon, D. P., \& Dwyer, J. H. (1993). Estimating mediated effects in prevention studies. Evaluation Review, 17, 144-158.

Malott, K. M., Alessandria, K. P., Kirkpatrick, M., \& Carandang, J. (2009). Ethnic labeling in Mexican-origin youth: A qualitative assessment. Professional School Counseling, 12, 352-364.

Massey, D. S., \& Capoferro, C. (2008). The geographic diversification of American immigration. In D. S. Massey (Ed.), New faces in new places: The changing geography of American immigration (pp. 25-50). New York: Russell Sage.

Masuoka, N. (2006). Together they become one: Examining the predictors of panethnic group consciousness among Asian Americans and Latinos. Social Science Quarterly, 87, 993-1011.

Morales, A., \& Hanson, W. E. (2005). Language brokering: An integrative review of the literature. Hispanic Journal of Behavioral Sciences, 27, 471-503.

North Carolina Department of Public Instruction (2008). Data and statistics. Retrieved Oct. 27, 2008 from www.dpi.state.nc.us/ data/reports.

Okamoto, D. G. (2006). Institutional panethnicity: Boundary formation in Asian-American organizing. Social Forces, 85, 1-25.

Orellana, M. F. (2003). Responsibilities of children in Latino immigrant homes. New Directions for Youth Development, $100,25-39$.

Parrado, E. A., \& Kandel, W. (2008). New Hispanic migrant destinations: A tale of two industries. In D. S. Massey (Ed.), New faces in new places: The changing geography of American immigration (pp. 99-123). New York: Russell Sage.

Perreira, K. M., Fuligni, A. J., \& Potochnick, S. (2010). Fitting in: The roles of social acceptance and discrimination in shaping the academic motivations of Latino youth in the U.S. Southeast. Journal of Social Issues, 66, 131-153.

Perry, M. J., \& Schachter, J. P. (2003). Migration of natives and the foreign born: 1995-2000.

Phinney, J. S. (2003). Ethnic identity and acculturation. In K. M. Chun, P. B. Organista, \& G. Marin (Eds.), Acculturation: Advances in theory, measurement, and applied research (pp. 63-81). Washington, DC: American Psychological Association.

Phinney, J. S., Romero, I., Nava, M., \& Huang, D. (2001). The role of language, parents and peers in ethnic identity among adolescents in immigrant families. Journal of Youth and Adolescence, 30, 135-153.
Portes, A., \& Rumbaut, R. G. (2001). Legacies: The story of the immigrant second generation. New York: Russell Sage Foundation.

Qian, Z. (2004). Options: Racial/ethnic identification of children of intermarried couples. Social Science Quarterly, 85, 746-766.

Reeves, T., \& Bennett, C. (2003). The Asian and Pacific Islander population in the United States: March 2002. Current Population Reports, P20-540, U.S. Washington, DC: Census Bureau.

Rosenberg, M. (1965). Society and the adolescent self-image. Princeton, NJ: Princeton University Press.

Rumbaut, R. G. (1994). The crucible within: Ethnic identity, selfesteem and segmented assimilation among children of immigrants. International Migration Review, 28, 748-794.

Ryff, C. D., Keyes, C. L. M., \& Hughes, D. L. (2003). Status inequalities, perceived discrimination, and eudaimonic wellbeing: Do the challenges of minority life hone purpose and growth? Journal of Health and Social Behavior, 44, 275-290.

Sellers, R. M., Rowley, S. J., Chavous, T. M., Shelton, J. N., \& Smith, M. A. (1997). Multidimensional inventory of black identity: A preliminary investigation of reliability and construct validity. Journal of Personality and Social Psychology, 73, 805-815.

Suro, R., \& Tafoya, S. (2004). Dispersal and concentration: Patterns of Latino residential settlement. Washington, DC: Pew Hispanic Center.

US Census (2004). Vintage 2004 archive. Retrieved on January 12, 2007 from www.census.gov/popest/archives/2000s/vintage_2004.

Zarate, M. E., Bhimji, F., \& Reese, L. (2005). Ethnic identity and academic achievement among Latino/a Adolescents. Journal of Latinos and Education, 4, 95-114.

\section{Author Biographies}

Lisa Kiang is Assistant Professor of Psychology at Wake Forest University. Her area of research is in cultural identity and social relationships, with an emphasis on positive well-being in ethnically diverse adolescents.

Krista M. Perreira is Associate Professor at the Carolina Population Center at UNC-Chapel Hill. She is an immigration scholar and demographer who studies disparities in health, education, and economic well-being.

Andrew J. Fuligni is Professor of Psychology and Psychiatry at the University of California, Los Angeles. Dr. Fuligni's research has focused on family relationships and adolescent development among culturally and ethnically diverse populations. 